\title{
Interest in Continuing Surgical Activity-A Necessity During the Pandemic
}

\author{
Shingai Bertrand Angelo Mutambirwa \\ Sefako Makgatho Health Sciences University—Urology, Pretoria, Gauteng, South Africa
}

Correspondence to: Shingai Bertrand Angelo Mutambirwa; email: sbmutambirwa@hotmail.com, shingai.mutambirwa@smu.ac.za

Received: 26 January 2021; Revised: 12 March 2021; Accepted: 22 March 2021; Available online: 27 March 2021

Keywords: Pandemic, Covid-19, Surgical activity

Ann Afr Surg. 2021; 18(2): 67-68

DOI: http://dx.doi.org/10.4314/aas.v18i2.1

Conflicts of Interest: None

Funding: None

(C) 2021 Author. This work is licensed under the Creative Commons Attribution 4.0 International License

As the COVID-19 pandemic continues, surgeons, as with all other medical practitioners, must not lose sight of the standard care and management that we must continue to deliver to safeguard our patients and communities from dereliction of medical duty.

During the Ebola epidemic, secondary epidemics of diseases amenable to vaccination may have occurred(1). While the paper by Fortes et al.(2) reports on traumatic conditions in the period before the pandemic, it would be interesting to see if there are any changes in the presentation of these cases during this crisis.

Although deaths from cancer have decreased, this is postulated to be due to the lack of presentation and screening(3). In addition, the discrepancies in health care, including in surgery, will only become apparent when or if we reach the end of the pandemic, requiring a global change in attitude and innovation to address this(4).

The toll on medical practitioners' mental and physical health cannot be underplayed. This too needs to be addressed with concerted effects in the medical fraternity as well as by civil society and governments worldwide (5).

Despite the challenges of the pandemic, medical education must continue to assure us of the next generation of healthcare workers. The two papers by
Ojuka et al. $(6,7)$ provide insights into medical training and the perceptions of medical students. The papers by Yani et al.(8) and Rihan et al.(9) illustrate the need for continued investigation of common conditions and surgical procedures to try and improve patient outcomes. The use of molecular imaging and genetics-an innovation in epidemiological studies - has made huge strides on the African continent, though there is still more to be done.

With all these in mind, this edition of The Annals of African Surgery offers a range of topics addressing various surgical issues from surgical disciplines in Africa and globally. The Annals of African Surgery always strives to present the best and most interesting and engaging articles for the readership, and this edition is no exception.

We hope that you enjoy the papers in this edition. Keep safe even as you continue to manage patients and conduct research.

\section{References}

1. Colavita F, Biava M, Castilletti C, Quartu S, et al. Measles cases during Ebola outbreak, West Africa, 2013-2016. Emerg Infect Dis. 2017;23:1035-7.

2. Fortes NAH, Yohannan P. Clinical and epidemiological profile of oral and maxillofacial trauma at two quaternary 
hospitals in Mozambique in 2016. Ann Afr Surg. 2021;18(2): 85-89

3. Bakouny Z, Paciotti M, Schmidt AL, et al. Cancer screening tests and cancer diagnoses during the COVID19 pandemic. JAMA Oncol. 2021;7:458-60.

4. Hardcastle TC, Chu KM. Global surgery: a South African plan. S Afr J Surg. 2020;58:176-7.

5. Mukhtar S. Psychological health during the coronavirus disease 2019 pandemic outbreak. Int J Psychiatry. 2020;66:512-6.

6. Ojuka D, Bonareri F, Githambo B, et al. The Medical Education Environment at the University of Nairobi, Kenya: an assessment with the DREEM tool. Ann Afr Surg. 2021; 18(2): 96-102.

7. Ojuka D, Bonareri F, Githambo B, et al. Medical students' perceptions of the medical education learning environment at the University of Nairobi: A qualitative study. Ann Afr Surg. 2021; 18(2): 103-108

8. Yani A, Dorothy D, Amaliah R. Influence of intestinal strangulation release on ischemia-reperfusion injury in Sprague-Dawley Rat. Ann Afr Surg. 2021;18(2): 90-95

9. Rihan M. Prepuce transillumination: a safety tool in forceps-guided circumcision. Ann Afr Surg. 2021;18(2): $75-78$ 